ENCYCLOPEDDIE Encyclopédie berbère

BERBERE

8 | 1990

8 | Aurès - Azrou

\title{
Azemmur : « olives, olivier »
}

(linguistique)

S. Chaker

\section{(2) OpenEdition}

Journals

Édition électronique

URL : http://journals.openedition.org/encyclopedieberbere/218

DOI : $10.4000 /$ encyclopedieberbere.218

ISSN : 2262-7197

Éditeur

Peeters Publishers

Édition imprimée

Date de publication : 1 juillet 1990

Pagination : 1220-1221

ISBN : 2-85744-461-3

ISSN : $1015-7344$

Référence électronique

S. Chaker, «Azemmur : « olives, olivier » », Encyclopédie berbère [En ligne], 8 | 1990, document A346, mis en ligne le 20 avril 2011, consulté le 24 septembre 2020. URL : http://journals.openedition.org/ encyclopedieberbere/218; DOI : https://doi.org/10.4000/encyclopedieberbere.218

Ce document a été généré automatiquement le 24 septembre 2020.

(c) Tous droits réservés 


\section{Azemmur : « olives, olivier »}

\section{(linguistique)}

\section{S. Chaker}

1 Terme attesté dans la généralité des parlers berbères maghrébins (Dj. Nefousa, Aurès, Kabylie, Maroc central, Rif, domaine chleuh...), désignant les « oliviers » (collectif) et les « olives ».

2 Sa distribution dans tous les dialectes de la zone méditerranéenne du monde berbère où se pratique la culture de l'olivier - et la stabilité absolue de sa forme (azemmur)sont des gages de son ancienneté et de son caractère autochtone. On peut y voir aussi un indice lexical de l'ancienneté de cette culture au Maghreb.

Dans les dialectes «occidentaux» (Beni Snous: Destaing, 1914, p. 252 ; Rif : Esteban Ibanez, 1944, p. 305 ; Maroc central: Mercier, 1937, p. 180 ; Chleuh : Destaing, 1920, p. 204), le terme désigne précisément l'«olivier sauvage, non greffé». Azemmur signifiait donc sans doute à l'origine «oléastre»-qui pousse spontanément au Maghreb. Le mot a pris le sens «olivier» dans les régions orientales du domaine berbère, où la culture de l'olivier est certainement beaucoup plus ancienne et plus intense - sous l'influence punique puis romaine - et a gardé sa signification primitive à l'ouest. A travers cette répartition sémantique transparaît peut-être l'histoire de la diffusion d'une pratique agricole.

4 Sa signification et sa généralité expliquent bien sûr la fréquence de ses attestations dans la toponymie du Maghreb et des zones d'influence maghrébine comme l'Espagne musulmane (Zamora...).

5 Le nom de la tribu marocaine (Maroc central) des Zemmur* pourrait être une forme ancienne de ce mot, sans la voyelle initiale caractéristique du nom berbère actuel. La genèse sémantique d'une telle dénomination pour un groupe humain reste évidemment obscure; elle renvoie peut-être à une signification plus ancienne encore de la racine ZMR, connue par ailleurs en berbère avec le sens de "pouvoir, être capable, supporter ». 


\section{BIBLIOGRAPHIE}

BEGUINOT F., Il Berbero Nefûsi di Fassâto, Roma, 1931, p. 263.

DALLET J.M., Dictionnaire kabyle-français, Paris, 1982, p. 948.

DESTAING E., Vocabulaire français-berbère (tachelhit du Sous), Paris, 1920, p. 204.

DESTAING E., Vocabulaire français-berbère (dialecte des Beni-Snous), Paris, 1914, p. 252.

ESTEBAN IBANEZ FR., Diccionario espaol-rifeño, Madrid, 1944, p. 305.

HUYGHE R.P., Dictionnaire français-chaouï, 1906, p. 455.

LAOUST E., Mots et choses berbères, Paris, 1920, p. 444 et sq.

MERCIER H., Vocabulaire et textes berbères (Ait Izdeg), Rabat, 1937, P. 180.

INDEX

Mots-clés : Agriculture, Botanique, Linguistique 